\title{
Debt Financing vs. Managerial Delegation: Are They Substitutes or Complements?
}

\author{
Mustafa Yıldırım** \\ İzmir Kâtip Çelebi University
}

\begin{abstract}
There are two important but distinct literatures emphasizing the strategic values of debt financing and managerial delegation in oligopolistic markets. In this paper, I construct a unified model that allows firms to choose both. My main finding is that each firm views its debt and managerial delegation as substitute choices under quantity competition, and as complementary choices under price competition, regardless of products' being substitutes or complements.

Keywords: Capital structure, debt, leverage ratio, managerial compensation, oligopoly

JEL Classification: D43, G32, M52
\end{abstract}

\section{Yönetimsel Delegasyona Karşı Borç Finansmanı: İkameler mi Yoksa Tamamlayıcılar mı?}

\section{Özet}

Oligopol piyasalarda, borçlanma finansmanının ve yönetimsel delegasyonun stratejik değerini vurgulayan iki önemli ve farklı literatür bulunmaktadır. Bu çalışmada, firmaların her ikisini de seçmelerine izin veren birleştirilmiş bir model kurmaktayım. Ana bulgum, ürünlerin ikame veya tamamlayıcı olmasından bağımsız olarak, her bir firmanın borcunu ve yönetimsel delegasyonunu miktar rekabeti altında ikame seçenekler ve fiyat rekabeti altında tamamlayıcı seçenekler olarak gördüğüdür.

Anahtar Kelimeler: Borç, kaldıraç oranı, oligopol, sermaye yapısı, yönetici ücretleri

JEL Sinıflandırmasi: D43, G32, M52

\footnotetext{
* I thank Refik Erzan (the Editor-in-Chief), two anonymous referees, and Huseyin Yildirim for comments. All errors are mine.

** Mustafa Yıldırım Assistant Professor Department of Economics İzmir Kâtip Çelebi University Balatçık Kampüsü, Çiğli, 35620, İzmir, Turkey Tel: +90 232329 3535, ext. 3263; Fax: +90 2323860888

E-mail:mustiyildirim@gmail.com Website: https://hhs.academia.edu/MustafaYILDIRIM
} 


\section{Introduction}

Beginning with the seminal work of Brander and Lewis (1986), there emerged extensive literature that investigates how oligopolistic firms may choose their capital structures to gain a competitive advantage in the product market. ${ }^{1}$ Brander and Lewis (1986) proposed that limited liable firms may excessively lean toward debt financing to credibly convey to the rivals that they will be aggressive in the product market to pay their debts. In addition to the choice of financial structure, the choice of the internal structure may also allow firms to commit to being aggressive in the product market. In their pioneering papers, Fershtman and Judd (1987) and Sklivas (1987) argued that in large companies, the owners might strategically design their managers' compensation schemes so that managers would behave more aggressively in the product market than the owners would. The reason is that whereas by being the residual claimants, the owners are known to maximize profits, managers' compensations can be manipulated to deviate from this objective toward sales maximization. ${ }^{2}$

Given the importance of both financial and internal structures, in this paper, I construct a unified model featuring both structures of firms and examine the interaction between the two. My main result is that while oligopolistic firms employ financial and internal structures as substitutes under quantity competition, they employ them as complements under price competition. In particular, my analysis reveals that if firms in a sector are highly debt-leveraged, then those firms are likely to make their managerial compensation less sensitive to performance if the competition is in quantity but more so if the competition is in price. Conversely, if firms in a sector offer steep compensation packages, then these firms are unlikely to use high debt leverage with quantity competition and low debt leverage with price competition. These findings are consistent with the empirical studies that examine managerial compensation in light of the firm's leverage. For instance, Pi and Timme (1993) documented that in a banking industry, which is a highly leveraged sector, the pay-for-performance sensitivity is close to zero. Similarly, Gilson and Vetsuypens (1993) showed that the pay-for-performance sensitivity dramatically declines as firms become financially distressed. More recently, Ortiz-Molina (2007) also showed the negative association between the pay-for-performance sensitivity and firm's leverage.

Apart from the works discussed above, the current paper relates to the theoretical work of Brander and Poitevin (1992) which points out that managerial contracts can be important determinants of the optimal financial structure as in the current study. Unlike in the present study, however, Brander and Poitevin derive a managerial compensation contract that leads to a local irrelevance result for the financial structure in the sense of Modigliani and Miller (1958). This irrelevance result is due to their modeling framework that differs from the current study in many ways, including the type of managerial compensation schemes assumed.

The rest of this paper is organized as follows. The model is described in the next section. All formal results appear in Sections 3 and 4, where I present the results for quantity competition and price competition, respectively. Section 5 concludes.

\footnotetext{
${ }^{1}$ Most recent papers following Brander and Lewis (1986) include Maksimovic (1988), Showalter (1995), Damania (1997), Dasgupta and Titman (1998), and Faure-Grimaud (2000). For a survey of this literature, see Harris and Raviv (1991).

${ }^{2}$ That is, a profit-maximizing strategy may not actually maximize profits when firms compete in a product market. Thus, the presence of managers allows the owners to raise profits by adopting a more aggressive, sales-oriented strategy. See Kräkel (2005) for an application of this strategy to tournaments.
} 


\section{The Model}

Consider a two-stage game $(t=1,2)$ between two rival firms $(i=1,2)$, operating in a differentiated product market with uncertain demand (elaborated below). Each firm has one risk-neutral owner (she) and one risk-neutral manager (he) with limited liability. At $t=1$, the owners simultaneously choose their debt levels $\left(D_{1}, D_{2}\right)$ as well as their managerial contracts $\left(M_{1}, M_{2}\right)$ to maximize expected profits. ${ }^{3}$ As in Fershtman and Judd (1987) and Sklivas (1987), the contracts are assumed to be linear in firm $i$ 's profit $\left(\pi_{i}\right)$ and revenue $\left(R_{i}\right)$ net of its debt $\left(D_{i}\right)$ to the extent of limited liability. Specifically, the compensation for manager $i$ takes the following form:

$$
M_{i} \equiv \max \left\{0,\left(1-r_{i}\right) \pi_{i}+r_{i} R_{i}-D_{i}\right\}
$$

where $r_{i} \geq 0$ measures the "delegation level" in firm $i$ since, clearly, its manager's incentives to deviate from profit maximization grows with $r_{i}{ }^{4}$ Letting $C_{i} \equiv C_{i}\left(q_{i}\right)$ denote firm $i$ 's cost of production, (1) can be rewritten as

$$
M_{i}=\max \left\{0, R_{i}-\left(1-r_{i}\right) C_{i}-D_{i}\right\}
$$

which implies that, with more delegation, the costs are weighed less by the manager.

At $t=2$, upon publicly observing debt levels and incentive contracts, managers simultaneously set their quantities $\left(q_{1}, q_{2}\right)$ or prices $\left(p_{1}, p_{2}\right)$ to maximize their expected compensation, depending on the mode of competition.

It is worth noting that the use of managerial contracts in (1) requires some uncertainty about the demand; otherwise, simple quantity- or price-based contracts would render their use irrelevant. Therefore, following the literature, I also assume that owners cannot directly observe the managerial decisions.

As usual, I solve this two-stage game for subgame perfect equilibrium (henceforth equilibrium), beginning with the second stage in which managers compete in quantity.

\section{Quantity Competition}

As in the literature (e.g., Sklivas 1987), I assume linear demand:

$$
p_{i}=a_{i}-q_{i}-b q_{-i}
$$

\footnotetext{
${ }^{3}$ As in Brander and Lewis (1986), I assume that the owners abstract from alternative considerations of debt financing such as its tax advantage, financial distress costs, and its use in capital investments.

${ }^{4} M_{i}$ need not be the actual payment manager $i$ receives. In general, manager $i$ 's compensation can be $A_{i}+B_{i} M_{i}$ for some constants $A_{i}$, $B_{i}$, with $B_{i}>0$ so that his participation is ensured.
} 
where $|b|<1$, and $a_{i}$ is independently drawn from a uniform distribution: $a_{i} \sim U\left[a_{l}, a_{u}\right]$. Evidently, $b<0$ refers to complementary, and $b>0$ refers to substitute goods. I also assume a linear cost: $C_{i}\left(q_{i}\right)=c_{i} q_{i}$.

Defining the cut-off state for demand

$$
\hat{a}_{i}=q_{i}+b q_{-i}+\left(1-r_{i}\right) c_{i}+\frac{D_{i}}{q_{i}}
$$

and rearranging (2), manager $i$ 's compensation can be expressed as

$$
M_{i}=\left\{\begin{array}{lll}
\left(a_{i}-\hat{a}_{i}\right) q_{i} & \text { if } & a_{i} \geq \hat{a}_{i} \\
0 & \text { if } & a_{i}<\hat{a}_{i} .
\end{array}\right.
$$

In particular, due to limited liability, manager $i$ is not penalized in low demand states even though his earnings fall short of his debt.

At $t=2$, given the debt $\left(D_{1}, D_{2}\right)$, delegation levels $\left(r_{1}, r_{2}\right)$, and the rival's quantity $q_{-i}$, manager $i$ sets his firm's quantity $q_{i}$ to maximize his expected compensation:

$$
V_{i} \equiv \int_{\hat{a}_{i}}^{a_{u}} M_{i} \frac{1}{a_{u}-a_{l}} d a_{i}=\frac{\left(a_{u}-\hat{a}_{i}\right)^{2}}{2\left(a_{u}-a_{l}\right)} q_{i}
$$

where $\frac{1}{a_{u}-a_{l}}$ is the Uniform density and, assuming ${ }^{5} a_{l}<\hat{a}_{i}<a_{u}$, the second equation follows from (4).

I assume throughout an interior equilibrium in which all choices are positive. Using (3), the first-order condition of (5) requires

$$
\frac{\partial V_{i}}{\partial q_{i}}=\frac{a_{u}-\hat{a}_{i}}{2\left(a_{u}-a_{l}\right)}\left(-3 q_{i}+a_{u}-\left(1-r_{i}\right) c_{i}-b q_{-i}+\frac{D_{i}}{q_{i}}\right)=0
$$

or simply,

$$
-3 q_{i}+a_{u}-\left(1-r_{i}\right) c_{i}-b q_{-i}+\frac{D_{i}}{q_{i}}=0
$$

Solving (6), I obtain manager $i$ 's best-response:

\footnotetext{
${ }^{5}$ With small enough $a_{l}$ and large enough $a_{u}$, this assumption holds.
} 


$$
q_{i}=\frac{a_{u}-b q_{-i}-\left(1-r_{i}\right) c_{i}+\sqrt{\left(a_{u}-b q_{-i}-\left(1-r_{i}\right) c_{i}\right)^{2}+12 D_{i}}}{6}
$$

Moreover, solving (7) for $q_{1}$ and $q_{2}$, I find the equilibrium quantities $q_{1}^{*}$ and $q_{2}^{*}$ as functions of $D_{i}$ and $r_{i}$. Lemma 1 demonstrates that more debt and more delegation provide similar incentives to managers in equilibrium.

Lemma 1 Suppose both firms produce in equilibrium. Then, under quantity competition, regardless of products' being substitutes or complements, manager i's equilibrium quantity, $q_{i}^{*}$, is increasing in its own debt, $D_{i}$, and delegation level, $r_{i}$. Moreover, the rival's equilibrium quantity, $q_{-i}^{*}$, is decreasing (resp. increasing) in $D_{i}$ and $r_{i}$ if the products are substitutes (resp. complements).

To understand Lemma 1, note from (7) that an increase in firm $i$ 's debt or its delegation level makes its manager more aggressive in production: an additional debt elevates this aggressive behavior by raising the cut-off state, $\hat{a}_{i}$, as this would cause the limited liable manager to focus only on high demand states. On the other hand, increased delegation elevates the same aggressive behavior by reducing the manager's perceived production cost. ${ }^{6}$ That is, the intuition exclusively given for debt in Brander and Lewis (1986) and exclusively given for delegation in Fershtman and Judd (1987) continues to hold in the unified setup for both substitute and complementary products. In particular, Lemma 1 adds the case of complements to their intuition. Since the rival manager responds to manager $i$ by decreasing his production when products are substitutes, and by increasing it when they are complements, the last part of Lemma 1 also follows.

Armed with equilibrium quantities in the second stage, I now analyze the first stage in which owner $i$, taking $D_{-i}$ and $r_{-i}$ as given, jointly chooses $D_{i}$ and $r_{i}$ to maximize her expected profit:

$$
\begin{aligned}
O_{i} & =\int_{a_{l}}^{a_{u}} \pi_{i}\left(q_{i}^{*}, q_{-i}^{*}, a_{i}\right) \frac{1}{a_{u}-a_{l}} d a_{i} \\
& =\left(\frac{a_{l}+a_{u}}{2}-q_{i}^{*}-b q_{-i}^{*}-c_{i}\right) q_{i}^{*} .
\end{aligned}
$$

In an interior equilibrium, the respective first-order conditions $\operatorname{are}^{7}$

\footnotetext{
6 This reduced cost also imposes a negative impact by reducing the cut-off state for a reason opposite to the previous intuition, which, however, is offset by the increase in marginal returns.

7 Given the two-stage duopoly competition and no closed-form solutions, I am unable to prove the existence of an interior equilibrium. I, however, strongly conjecture that there is one since my model simply unifies two well-known strands of the literature building on Brander and Lewis (1986), Fershtman and Judd (1987), and Sklivas (1987), all of whom find or assume an interior equilibrium. In a numerical example, which is available upon request, I have shown that a duopolistic owner indeed has a local incentive for debt financing or delegation because doing so discourages the rival's production.
} 


$$
\frac{\partial O_{i}}{\partial D_{i}}=\left(\frac{a_{l}+a_{u}}{2}-2 q_{i}^{*}-b q_{-i}^{*}-c_{i}\right) \frac{\partial q_{i}^{*}}{\partial D_{i}}-b q_{i}^{*} \frac{\partial q_{-i}^{*}}{\partial D_{i}}=0
$$

and

$$
\frac{\partial o_{i}}{\partial r_{i}}=\left(\frac{a_{l}+a_{u}}{2}-2 q_{i}^{*}-b q_{-i}^{*}-c_{i}\right) \frac{\partial q_{i}^{*}}{\partial r_{i}}-b q_{i}^{*} \frac{\partial q_{-i}^{*}}{\partial r_{i}}=0 .
$$

From the proof of Lemma 1 (see the appendix), note that

$$
\frac{\partial q_{-i}^{*}}{\partial D_{i}}=\frac{-b}{3+\frac{D_{-i}}{\left(q_{-i}^{*}\right)^{2}}} \frac{\partial q_{i}^{*}}{\partial D_{i}} \quad \text { and } \quad \frac{\partial q_{-i}^{*}}{\partial r_{i}}=\frac{-b}{3+\frac{D_{-i}}{\left(q_{-i}^{*}\right)^{2}}} \frac{\partial q_{i}^{*}}{\partial r_{i}}
$$

and also that $\frac{\partial q_{i}^{*}}{\partial D_{i}}>0$ and $\frac{\partial q_{i}^{*}}{\partial r_{i}}>0$, reducing both (8) and (9) to the same equation:

$$
\frac{a_{l}+a_{u}}{2}-2 q_{i}^{*}-b q_{-i}^{*}-c_{i}+\frac{b^{2} q_{i}^{*}}{3+\frac{D_{-i}}{\left(q_{-i}^{*}\right)^{2}}}=0 \text {. }
$$

Since there are two unknowns but only one equation, namely (10), there is a continuum of $\left(D_{i}, r_{i}\right)$ pairs that are optimal for owner $i$. That is, given the rival's debt and delegation levels $\left(D_{-i}, r_{-i}\right)$, firm $i$ 's debt level, $D_{i}$, is a function of its delegation level, $r_{i}: D_{i}=\bar{D}_{i}\left(r_{i}\right)$. Proposition 1, which is my main result, shows the relationship between the two firm structures.

Proposition 1 Suppose the equilibrium is interior. Then, under quantity competition, given the rival's decisions, each owner views its debt and delegation decisions as substitutes, i.e., $\frac{\partial \bar{D}_{i}}{\partial r_{i}}<$ 0 , regardless of products' being substitutes or complements.

Proposition 1 seems to be in line with the findings of empirical studies cited in the Introduction insofar as the competition is considered to occur in quantity: a firm's leverage and its pay-for-performance sensitivity are inversely related. It is best understood by considering owners' incentives under the standard Stackelberg leadership. When products are substitutes, it is well-known that Stackelberg leader in quantity competition would commit to overproduction and enjoy the first-mover advantage; see, e.g., Romano and Yildirim (2005). However, since managers play a simultaneous game here, each owner, to induce her manager to behave like the Stackelberg leader, incentivizes him to commit to overproduction by increasing her firm's debt and/or delegation levels. Interestingly, the same intuition extends to complements because the Stackelberg leader would again commit to overproduction given the reduced coordination problem compared to the simultaneous play in this case. One testable prediction of Proposition 1 is that industries consisting of owner-managed firms such as family-owned companies are more likely to rely on debt-financing than those owned by shareholders.

Having established that debt and delegation levels serve as substitute choices under quantity competition, I next consider price competition where they turn out to be complementary choices. 


\section{Price Competition}

As in quantity competition, assume linear demand: $q_{i}=\alpha_{i}-p_{i}+\beta p_{-i}$, where $|\beta|<1$, and $\alpha_{i}$ is an independent draw from a uniform distribution: $\alpha_{i} \sim U\left[\alpha_{l}, \alpha_{u}\right]$, along with a linear cost $C_{i}\left(q_{i}\right)=c_{i} q_{i}$. Following a similar line of argument to above, manager $i$ 's compensation can be written:

$$
M_{i}=\left\{\begin{array}{lll}
\left(\alpha_{i}-\hat{\alpha}_{i}\right)\left(p_{i}-\left(1-r_{i}\right) c_{i}\right) & \text { if } & \alpha_{i} \geq \hat{\alpha}_{i} \\
0 & \text { if } & \alpha_{i}<\hat{\alpha}_{i}
\end{array}\right.
$$

where

$$
\hat{\alpha}_{i}=p_{i}-\beta p_{-i}+\frac{D_{i}}{p_{i}-\left(1-r_{i}\right) c_{i}}
$$

From here, assuming $\alpha_{l}<\hat{\alpha}_{i}<\alpha_{u}$, manager $i$ 's expected compensation is found to be

$$
V_{i}=\int_{\widehat{\alpha}_{i}}^{\alpha_{u}} M_{i} \frac{1}{\alpha_{u}-\alpha_{l}} d \alpha_{i}=\frac{\left(\alpha_{u}-\widehat{\alpha}_{i}\right)^{2}\left(p_{i}-\left(1-r_{i}\right) c_{i}\right)}{2\left(\alpha_{u}-\alpha_{l}\right)}
$$

At $t=2$, given the debt $\left(D_{1}, D_{2}\right)$ and delegation levels $\left(r_{1}, r_{2}\right)$, and the rival's price choice $p_{-i}$, manager $i$ solves

$$
\max _{p_{i}} V_{i}
$$

The first-order condition requires that

$$
\frac{\partial V_{i}}{\partial p_{i}}=\frac{\alpha_{u}-\widehat{\alpha}_{i}}{2\left(\alpha_{u}-\alpha_{l}\right)}\left(-3\left(p_{i}-\left(1-r_{i}\right) c_{i}\right)+\alpha_{u}-\left(1-r_{i}\right) c_{i}+\beta p_{-i}+\frac{D_{i}}{p_{i}-\left(1-r_{i}\right) c_{i}}\right)=0,
$$

or equivalently,

$$
-3\left(p_{i}-\left(1-r_{i}\right) c_{i}\right)+\alpha_{u}-\left(1-r_{i}\right) c_{i}+\beta p_{-i}+\frac{D_{i}}{p_{i}-\left(1-r_{i}\right) c_{i}}=0
$$

Solving (14), I obtain manager $i$ 's best-response:

$$
p_{i}=\left(1-r_{i}\right) c_{i}+\frac{\alpha_{u}-\left(1-r_{i}\right) c_{i}+\beta p_{-i}+\sqrt{\left(\alpha_{u}-\left(1-r_{i}\right) c_{i}+\beta p_{-i}\right)^{2}+12 D_{i}}}{6}
$$

The intersection of the two best-response functions leads to the equilibrium price $p_{1}^{*}$ and $p_{2}^{*}$ as functions of $D_{i}$ and $r_{i}$. Lemma 2 shows that unlike in quantity competition, the debt and delegation level provide opposite incentives to managers. 
Lemma 2 Suppose both firms produce in equilibrium. Then, under price competition, (a) $p_{i}^{*}$ is increasing in $D_{i}$ and decreasing in $r_{i}$, regardless of products' being complements or substitutes,

(b) $p_{-i}^{*}$ is increasing (resp. decreasing) in $D_{i}$ and decreasing (resp. increasing) in $r_{i}$ for substitute (resp. complementary) products.

To understand Lemma 2, consider substitute goods, $\beta>0$. Note from (15) that the best-response curves are upward-sloping in this case: if manager $i$ lowers price, the rival follows suit. Note also that while a higher $D_{i}$ causes an upward shift in manager $i$ 's best-response, a higher $r_{i}$ causes a downward shift, explaining both parts (a) and (b). Intuitively, to pay for a higher debt, manager $i$ focuses on higher demand states and raises his price toward the collusive level, which the rival manager accommodates. ${ }^{8}$ On the other hand, as noted before, more delegation through a higher $r_{i}$ reduces manager $i$ 's perceived marginal cost, leading him to lower his price, which is again accommodated by the rival. The intuition for complementary goods follows by recalling that the best-response curves are downward-sloping in that case.

Taking $D_{-i}$ and $r_{-i}$ as given, owner $i$ jointly chooses $D_{i}$ and $r_{i}$ to maximize her expected profit:

$$
\begin{gathered}
O_{i}=\int_{\alpha_{l}}^{\alpha_{u}} \pi_{i}\left(p_{i}^{*}, p_{-i}^{*}, \alpha_{i}\right) \frac{1}{\alpha_{u}-\alpha_{l}} d \alpha_{i} \\
=\left(\frac{\alpha_{l}+\alpha_{u}}{2}-p_{i}^{*}+\beta p_{-i}^{*}\right)\left(p_{i}^{*}-c_{i}\right) .
\end{gathered}
$$

Employing the following findings from the proof of Lemma 2,

$$
\begin{gathered}
\frac{\partial p_{-i}^{*}}{\partial D_{i}}=\frac{\beta}{3+\frac{D_{-i}}{\left(p_{-i}-\left(1-r_{-i}\right) c_{-i}\right)^{2}}} \frac{\partial p_{i}^{*}}{\partial D_{i}}, \frac{\partial p_{-i}^{*}}{\partial r_{i}}=\frac{\beta}{3+\frac{D_{-i}}{\left(p_{-i}-\left(1-r_{-i}\right) c_{-i}\right)^{2}}} \frac{\partial p_{i}^{*}}{\partial r_{i}}, \\
\frac{\partial p_{i}^{*}}{\partial D_{i}}>0, \text { and } \frac{\partial p_{i}^{*}}{\partial r_{i}}<0,
\end{gathered}
$$

the first-order conditions

$$
\frac{\partial O_{i}}{\partial D_{i}}=\left(\frac{\alpha_{l}+\alpha_{u}}{2}-2 p_{i}^{*}+\beta p_{-i}^{*}+c_{i}\right) \frac{\partial p_{i}^{*}}{\partial D_{i}}+\beta\left(p_{i}^{*}-c_{i}\right) \frac{\partial p_{-i}^{*}}{\partial D_{i}}=0,
$$

and

$$
\frac{\partial o_{i}}{\partial r_{i}}=\left(\frac{\alpha_{l}+\alpha_{u}}{2}-2 p_{i}^{*}+\beta p_{-i}^{*}+c_{i}\right) \frac{\partial p_{i}^{*}}{\partial r_{i}}+\beta\left(p_{i}^{*}-c_{i}\right) \frac{\partial p_{-i}^{*}}{\partial r_{i}}=0,
$$

boil down to the same equation:

\footnotetext{
${ }^{8}$ Kovenock and Phillips (1995) empirically find that recapitalizing firms take a more passive stance in the output market and thus conclude that the limited liability explanations of Brander and Lewis (1986) is consistent with the evidence only under price competition.
} 


$$
\frac{\alpha_{l}+\alpha_{u}}{2}-2 p_{i}^{*}+\beta p_{-i}^{*}+c_{i}+\frac{\beta^{2}\left(p_{i}^{*}-c_{i}\right)}{3+\frac{D_{-i}}{\left(p_{-i}^{*}-\left(1-r_{-i}\right) c_{-i}\right)^{2}}}=0
$$

One equation in two unknowns ensures that $D_{i}=\bar{D}_{i}\left(r_{i}\right)$. Proposition 2 is the counterpart of Proposition 1 for price competition.

Proposition 2 Suppose the equilibrium is interior. Then, under price competition, given the rival's decisions, each owner views its debt and delegation decisions as complements, i.e., $\frac{\partial \bar{D}_{i}}{\partial r_{i}}>0$, regardless of products' being substitutes or complements.

The complementarity result under price competition stands in sharp contrast to the substitutability result under quantity competition obtained in Proposition 1. This contrast is attributable solely to the opposite effects of debt on the manager's aggressiveness in production for the two modes of competition. In particular, as alluded to above, when faced with an increase in his firm's debt, the limited liable manager becomes more aggressive in production under quantity competition but takes a less aggressive stance in production under price competition by raising the price. In response to the increased delegation in his firm, however, the manager always adopts a more aggressive position in both competition modes as it lowers the perceived marginal cost.

Proposition 2, along with Proposition 1, conveys a clear message: a firm's financial and internal structures are interrelated, and the exact relationship hinges on the mode of competition.

\section{Conclusion}

It is well-known that, in an oligopolistic market, a profit-maximizing firm can achieve higher profits by committing to objectives other than profit maximization. Such nonprofit-maximizing objectives can be formed by increasing the debt leverage of the firm as in Brander and Lewis (1986) or by managerial incentives for sales (revenue) maximization as in Fershtman and Judd (1987) and Sklivas (1987). This paper shows that oligopolistic firms' decisions regarding their financial and internal structures are closely related. Specifically, it shows that firms' choices of debt financing and their choices of managerial incentive payments act as substitute tools under quantity competition and as complementary tools under price competition, regardless of products' being substitutes or complements.

A direct implication of this result is that considering the choice of the managerial compensation scheme, firms may be relying on debt financing less than Brander and Lewis (1986) predict because part of an aggressive sales strategy is shifted toward the managers' incentive pay. Conversely, considering the choice of debt financing, managerial incentives may be flatter or steeper than Fershtman and Judd (1987) and Sklivas (1987) predict, depending on the mode of competition. Future research may fruitfully extend the present analysis to more general (nonlinear) compensation schemes and richer financial structures. 


\section{References}

Brander, J. A., \& Lewis, T. R. (1986). Oligopoly and financial structure: The limited liability effect. American Economic Review, 956-970.

Damania, D. (1997). Debt as a collusive device in an oligopoly supergame. Journal of Economics, 66(3), 249-269.

Dasgupta, S., \& Titman, S. (1998). Pricing strategy and financial policy. Review of Financial Studies, 11(4), 705-737.

Faure-Grimaud, A. (2000). Product market competition and optimal debt contracts: The limited liability effect revisited. European Economic Review, 44(10), 1823-1840.

Fershtman, C., \& Judd, K. L. (1987). Equilibrium incentives in oligopoly. American Economic Review, 927-940.

Gilson, S. C., \& Vetsuypens, M. R. (1993). CEO compensation in financially distressed firms: An empirical analysis. Journal of Finance, 48(2), 425-458.

Harris, M., \& Raviv, A. (1991). The theory of capital structure. Journal of Finance, 46(1), 297-355.

Kovenock, D., \& Phillips, G. (1995). Capital structure and product-market rivalry: How do we reconcile theory and evidence?. American Economic Review, 85(2), 403-408.

Kräkel, M. (2005). Strategic Delegation in Oligopolistic Tournaments. Review of Economic Design, 377-396.

Maksimovic, V. (1988). Capital structure in repeated oligopolies. RAND Journal of Economics, 389-407.

Modigliani, F., \& Miller, M. H. (1958). The cost of capital, corporation finance and the theory of investment. American Economic Review, 48(3), 261-297.

Ortiz-Molina, H. (2007). Executive compensation and capital structure: The effects of convertible debt and straight debt on CEO pay. Journal of Accounting and Economics, 43(1), 69-93.

Pi, L., \& Timme, S. G. (1993). Corporate control and bank efficiency. Journal of Banking \& Finance, 17(2), 515-530.

Romano, R., \& Yildirim, H. (2005). On the endogeneity of Cournot-Nash and Stackelberg equilibria: games of accumulation. Journal of Economic Theory, 120(1), 73-107.

Showalter, D. M. (1995). Oligopoly and financial structure: comment. American Economic Review, 647-653.

Sklivas, S. D. (1987). The strategic choice of managerial incentives. RAND Journal of Economics, 452-458. 


\section{Appendix}

Proof of Lemma 1. By definition, equilibrium quantities $\left(q_{i}^{*}, q_{-i}^{*}\right)$ simultaneously satisfy managers' first-order conditions given in (6):

$$
-3 q_{i}^{*}+a_{u}-\left(1-r_{i}\right) c_{i}-b q_{-i}^{*}+\frac{D_{i}}{q_{i}^{*}}=0
$$

and

$$
-3 q_{-i}^{*}+a_{u}-\left(1-r_{-i}\right) c_{-i}-b q_{i}^{*}+\frac{D_{-i}}{q_{-i}^{*}}=0 .
$$

Total differentiation of these two conditions with respect to $D_{i}$ and $r_{i}$ generates

$$
\left(-3-\frac{D_{i}}{q_{i}^{* 2}}\right) \frac{\partial q_{i}^{*}}{\partial D_{i}}-b \frac{\partial q_{-i}^{*}}{\partial D_{i}}=-\frac{1}{q_{i}^{*}},-b \frac{\partial q_{i}^{*}}{\partial D_{i}}+\left(-3-\frac{D_{-i}}{q_{-i}^{* 2}}\right) \frac{\partial q_{-i}^{*}}{\partial D_{i}}=0
$$

and

$$
\left(-3-\frac{D_{i}}{q_{i}^{* 2}}\right) \frac{\partial q_{i}^{*}}{\partial r_{i}}-b \frac{\partial q_{-i}^{*}}{\partial r_{i}}=-c_{i},-b \frac{\partial q_{i}^{*}}{\partial r_{i}}+\left(-3-\frac{D_{-i}}{q_{-i}^{* 2}}\right) \frac{\partial q_{-i}^{*}}{\partial r_{i}}=0,
$$

which, in turn, yield

$$
\begin{gathered}
\frac{\partial q_{i}^{*}}{\partial D_{i}}=\frac{\frac{1}{q_{i}^{*}}\left(3+\frac{D_{-i}}{q_{-i}^{* 2}}\right)}{\left(3+\frac{D_{i}}{q_{i}^{* 2}}\right)\left(3+\frac{D_{-i}}{q_{-i}^{* 2}}\right)-b^{2}}, \frac{\partial q_{i}^{*}}{\partial r_{i}}=\frac{\left(3+\frac{D_{-i}}{q_{-i}^{* 2}}\right) c_{i}}{\left(3+\frac{D_{i}}{q_{i}^{* 2}}\right)\left(3+\frac{D_{-i}}{q_{-i}^{* 2}}\right)-b^{2}}, \\
\frac{\partial q_{-i}^{*}}{\partial D_{i}}=\frac{-b}{3+\frac{D_{-i}}{q_{-i}^{* 2}}} \frac{\partial q_{i}^{*}}{\partial D_{i}}, \text { and } \frac{\partial q_{-i}^{*}}{\partial r_{i}}=\frac{-b}{3+\frac{D_{-i}}{q_{-i}^{* 2}} \frac{\partial q_{i}^{*}}{\partial r_{i}}}
\end{gathered}
$$

It is straightforward to see that $\frac{\partial q_{i}^{*}}{\partial D_{i}}, \frac{\partial q_{i}^{*}}{\partial r_{i}}>0$ for $b \in(-1,1), \frac{\partial q_{-i}^{*}}{\partial D_{i}}, \frac{\partial q_{-i}^{*}}{\partial r_{i}}>0$ for $b \in$ $(-1,0)$ and $\frac{\partial q_{-i}^{*}}{\partial D_{i}}, \frac{\partial q_{-i}^{*}}{\partial r_{i}}<0$ for $b \in(0,1)$, as desired. Q.E.D.

Proof of Proposition 1. Implicitly differentiating owner $i$ 's first-order condition, which, by (10), is

$$
\underbrace{\frac{a_{l}+a_{u}}{2}-2 q_{i}^{*}-b q_{-i}^{*}-c_{i}+\frac{b^{2} q_{i}^{*}}{3+\frac{D_{-i}^{*}}{\left(q_{-i}^{*}\right)^{2}}}}_{\equiv f}=0,
$$

gives 


$$
\begin{aligned}
\frac{\partial D_{i}}{\partial r_{i}} & =-\frac{\frac{\partial f}{\partial r_{i}}}{\frac{\partial f}{\partial D_{i}}} \\
& =-\frac{\frac{\partial f}{\partial q_{i}^{*}} \frac{\partial q_{i}^{*}}{\partial r_{i}}+\frac{\partial f}{\partial q_{-i}^{*}} \frac{\partial q_{-i}^{*}}{\partial r_{i}}}{\frac{\partial q_{i}^{*}}{\partial q_{i}^{*}}+\frac{\partial f}{\partial D_{i}}+\frac{\partial q_{-i}^{*}}{\partial D_{i}^{*}}}
\end{aligned}
$$

(A-3), along with (A-2) and (A-1), simplifies to

$$
\begin{gathered}
\frac{\partial D_{i}}{\partial r_{i}}=-\frac{\frac{\partial q_{i}^{*}}{\partial r_{i}}}{\frac{\partial q_{i}^{*}}{\partial D_{i}}} \\
=-c_{i} q_{i}^{*}<0 .
\end{gathered}
$$

Finally, note that the assumption of an interior equilibrium justifies the use of owner $i$ 's first-order condition with equality, as needed. Q.E.D.

Proof of Lemma 2. The proof is similar to that of Lemma 1. Equilibrium prices $\left(p_{i}^{*}, p_{-i}^{*}\right)$ solve managers' first-order conditions which, by (14), are:

and

$$
-3\left(p_{i}^{*}-\left(1-r_{i}\right) c_{i}\right)+\alpha_{u}-\left(1-r_{i}\right) c_{i}+\beta p_{-i}^{*}+\frac{D_{i}}{p_{i}^{*}-\left(1-r_{i}\right) c_{i}}=0
$$

$$
-3\left(p_{-i}^{*}-\left(1-r_{-i}\right) c_{-i}\right)+\alpha_{u}-\left(1-r_{-i}\right) c_{-i}+\beta p_{i}^{*}+\frac{D_{-i}}{p_{-i}^{*}-\left(1-r_{-i}\right) c_{-i}}=0
$$

Total differentiation of these two conditions with respect to $D_{i}$ and $r_{i}$ generates the following set of equations:

$$
\begin{gathered}
\left(-3-\frac{D_{i}}{\left(p_{i}^{*}-\left(1-r_{i}\right) c_{i}\right)^{2}}\right) \frac{\partial p_{i}^{*}}{\partial D_{i}}+\beta \frac{\partial p_{-i}^{*}}{\partial D_{i}}=-\frac{1}{p_{i}^{*}-\left(1-r_{i}\right) c_{i}}, \\
\beta \frac{\partial p_{i}^{*}}{\partial D_{i}}+\left(-3-\frac{D_{-i}}{\left(p_{-i}^{*}-\left(1-r_{-i}\right) c_{-i}\right)^{2}}\right) \frac{\partial p_{-i}^{*}}{\partial D_{i}}=0, \\
\left(-3-\frac{D_{i}}{\left(p_{i}^{*}-\left(1-r_{i}\right) c_{i}\right)^{2}}\right) \frac{\partial p_{i}^{*}}{\partial r_{i}}+\beta \frac{\partial p_{-i}^{*}}{\partial r_{i}}=\left(2+\frac{D_{i}}{\left(p_{i}^{*}-\left(1-r_{i}\right) c_{i}\right)^{2}}\right) c_{i},
\end{gathered}
$$

and 


$$
\beta \frac{\partial p_{i}^{*}}{\partial r_{i}}+\left(-3-\frac{D_{-i}}{\left(p_{-i}^{*}-\left(1-r_{-i}\right) c_{-i}\right)^{2}}\right) \frac{\partial p_{-i}^{*}}{\partial r_{i}}=0
$$

These equations produce

$$
\begin{aligned}
\frac{\partial p_{i}^{*}}{\partial D_{i}} & =\frac{\frac{1}{p_{i}^{*}-\left(1-r_{i}\right) c_{i}}\left(3+\frac{D_{-i}}{\left(p_{-i}^{*}-\left(1-r_{-i}\right) c_{-i}\right)^{2}}\right)}{\left(3+\frac{D_{-i}}{\left(p_{i}^{*}-\left(1-r_{i}\right) c_{i}\right)^{2}}\right)\left(3+\frac{D_{-i}}{\left(p_{-i}^{*}-\left(1-r_{-i}\right) c_{-i}\right)^{2}}\right)-\beta^{2}} \\
\frac{\partial p_{i}^{*}}{\partial r_{i}} & =\frac{-\left(3+\frac{D_{i}}{\left(p_{-i}-\left(1-r_{-i}\right) c_{-i}\right)^{2}}\right)\left(2+\frac{D_{i}}{\left(p_{i}-\left(1-r_{i}\right) c_{i}\right)^{2}}\right) c_{i}}{\left(3+\frac{D_{-i}}{\left(p_{i}-\left(1-r_{i}\right) c_{i}\right)^{2}}\right)\left(3+\frac{1}{\left(p_{-i}-\left(1-r_{-i}\right) c_{-i}\right)^{2}}\right)-\beta^{2}}
\end{aligned}
$$

And

$$
\begin{aligned}
& \frac{\partial p_{-i}^{*}}{\partial D_{i}}=\frac{\beta}{3+\frac{D_{-i}}{\left(p_{-i}-\left(1-r_{-i}\right) c_{-i}\right)^{2}}} \frac{\partial p_{i}^{*}}{\partial D_{i}^{\prime}} \\
& \frac{\partial p_{-i}^{*}}{\partial r_{i}}=\frac{\beta}{3+\frac{D_{-i}}{\left(p_{-i}-\left(1-r_{-i}\right) c_{-i}\right)^{2}}} \frac{\partial p_{i}^{*}}{\partial r_{i}},
\end{aligned}
$$

where clearly, $\frac{\partial p_{i}^{*}}{\partial D_{i}}>0>\frac{\partial p_{i}^{*}}{\partial r_{i}}$ for $\beta \in(-1,1), \frac{\partial p_{-i}^{*}}{\partial D_{i}}<0<\frac{\partial p_{-i}^{*}}{\partial r_{i}}$ for $\beta \in(-1,0)$, and $\frac{\partial p_{-i}^{*}}{\partial D_{i}}>0>\frac{\partial p_{-i}^{*}}{\partial r_{i}}$ for $\beta \in(0,1)$. Q.E.D.

Proof of Proposition 2. As in the proof of Proposition 1, implicitly differentiate owner $i$ 's first-order condition given by (16),

$$
\underbrace{\frac{\alpha_{l}+\alpha_{u}}{2}-2 p_{i}^{*}+\beta p_{-i}^{*}+c_{i}+\frac{\beta^{2}\left(p_{i}^{*}-c_{i}\right)}{3+\frac{D_{-i}^{*}}{\left(p_{-i}^{*}-\left(1-r_{-i}^{*}\right) c_{-i}\right)^{2}}}}_{\equiv g}=0,
$$

to obtain

$$
\frac{\partial D_{i}^{*}}{\partial r_{i}}=-\frac{\frac{\partial g}{\partial r_{i}}}{\frac{\partial g}{\partial D_{i}}}
$$


(A-6), together with (A-5) and (A-4), simplify to

$$
=-\frac{\frac{\partial g}{\partial p_{i}^{*}} \frac{\partial p_{i}^{*}}{\partial r_{i}}+\frac{\partial g}{\partial p_{-i}^{*}} \frac{\partial p_{-i}^{*}}{\partial r_{i}}}{\frac{\partial g}{\partial p_{i}^{*}} \frac{\partial p_{i}^{*}}{\partial D_{i}}+\frac{\partial g}{\partial p_{-i}^{*}} \frac{\partial p_{-i}^{*}}{\partial D_{i}}}
$$

$$
\begin{gathered}
\frac{\partial D_{i}^{*}}{\partial r_{i}}=-\frac{\frac{\partial p_{i}^{*}}{\partial r_{i}}}{\frac{\partial p_{i}^{*}}{\partial D_{i}}} \\
=c_{i}\left(\frac{D_{i}}{p_{i}^{*}-\left(1-r_{i}\right) c_{i}}+2\left(p_{i}^{*}-\left(1-r_{i}\right) c_{i}\right)\right)>0 .
\end{gathered}
$$

Lastly, assuming the equilibrium to be interior assures the use of owner $i$ 's first-order condition with equality. Q.E.D. 